\title{
In-situ Microcompression Experiments: Examination of Lateral Constraint Effects
}

\author{
P.A. Shade ${ }^{*,{ }^{* *},{ }^{* * *}, \text { R. Wheeler }}{ }^{* * *}$, Y.S. Choi ${ }^{* * * *}$, M.D. Uchic ${ }^{*}$, D.M. Dimiduk ${ }^{*}$, H.L \\ Fraser $^{* *}$ \\ *Air Force Research Laboratory, Materials and Manufacturing Directorate, $223010^{\text {th }}$ \\ Street, Wright-Patterson AFB, OH 45433, USA \\ ** Department of Materials Science and Engineering, The Ohio State University, 477 \\ Watts Hall, 2041 College Road, Columbus, OH 43210, USA \\ ${ }^{* * *}$ Universal Technology Corporation, 1270 N Fairfield Road, Dayton, OH 45432, USA \\ ${ }^{* * * *}$ UES Inc., 4401 Dayton-Xenia Road, Dayton, OH 45432, USA
}

Seven years ago, some of the present authors developed a test methodology for measuring the flow behavior of miniature samples in compression [1]. The methodology consists of fabricating micrometer-scale cylindrical samples using focused ion beam (FIB) milling and subsequent testing of these samples in uniaxial compression with a commercial nanoindentation system outfitted with a flat punch tip. As a logical extension of this work, we have constructed a custom device for performing uniaxial mechanical tests on micrometer-scale specimens that can operate inside a scanning electron microscope (SEM) [2]. The in-situ device enables access to both tensile and compressive test modes, and facilitates the direct observation of the spatial and temporal distribution of deformation events through continuous recording of SEM images.

This presentation will describe the application of this device to study the compressive deformation behavior of single-slip oriented nickel superalloy (Rene N5) microcrystals. Initial experiments demonstrated that the loading platen and the top surface of the microcompression sample move as a single conjoined unit throughout a test, unlike macro-scale experiments where the sample slides against the compression platens. The lower end of the microcompression sample is integrally-connected to the substrate, and therefore the constraint imposed by the lateral stiffness of the loading platen significantly influences the resultant mechanical behavior.

This presentation will highlight the use of two different compression platens to explore the effect of lateral stiffness on the resultant mechanical response, which approximated either a high-friction or zero-friction case, as shown in Fig 1. The change in the lateral constraint of the test system had a demonstrable effect on many aspects or attributes of plastic flow: the yield stress and strain hardening behavior, the intermittency of strain bursts, the spatial distribution of slip bands, and the development of internal crystal rotations. Finite element modeling of the microcompression experiments using a crystal plasticity framework has provided insight regarding changes in the internal stress field and resultant slip system activity. The experimental tests findings are rationalized based on these simulation results. 


\section{References}

[1] M.D. Uchic et al., Science 305 (2004) 986-989.

[2] M.D. Uchic et al., Scripta Mater. 54 (2006) 759-764.

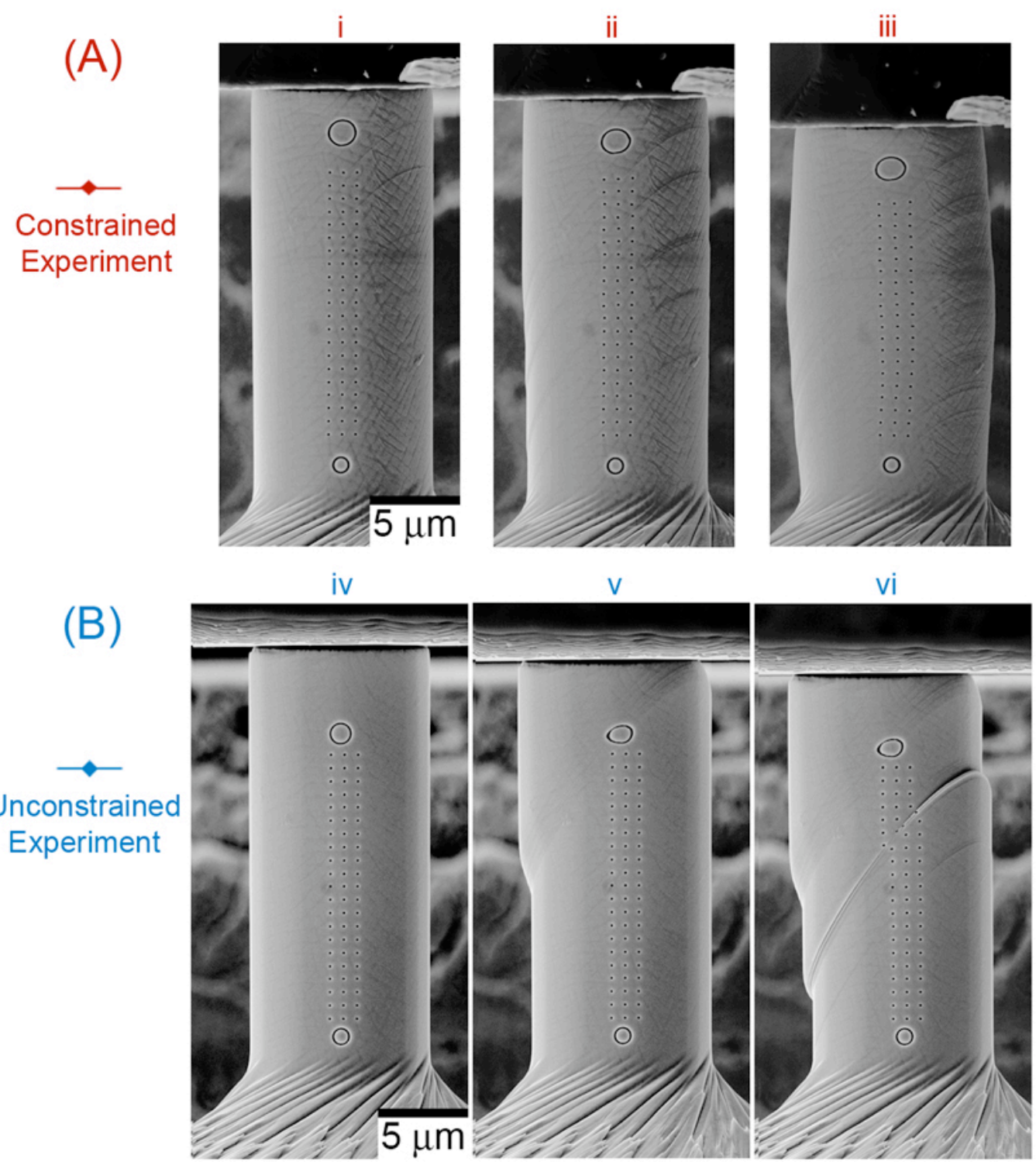

Figure 1. Scanning Electron Microscope images from two in-situ micro-compression experiments. The microcrystals are from a nickel base superalloy (Rene N5) oriented for single slip, and the microcrystal diameter is $10 \mu \mathrm{m}$. (A) Three SEM images at various strain levels while employing a high lateral stiffness diamond platen. (B) Three SEM images at various strain levels while employing a low lateral stiffness platen. 